Thorax (1975), 30, 539.

\title{
Oesophagomyotomy for achalasia of the cardia
}

\author{
C. S A R I Y A N N IS and K. S. MULLAR D \\ Cardiothoracic Unit, Southampton University Hospitals
}

\begin{abstract}
Sariyannis, C. and Mullard, K. S. 1975). Thorax, 30, 539-542. Oesophagomyotomy for achalasia of the cardia. Experience of 48 cases of achalasia of the cardia, treated by oesophagomyotomy, and of three cases of failed 'Heller' operation, treated by jejunal interposition, is recorded. Some technical details and the results are discussed.
\end{abstract}

Achalasia of the cardia, a disease of unknown aetiology, is characterized by irregular contractions of the oesophagus and abnormal responses to swallowing (Butin et al., 1953; Kramer, Ingelfinger, and Atkinson, 1956; Code and Schlegel, 1963). Because there is no known method by which oesophageal peristalsis can be restored, therapy is directed towards the relief of the distal oesophageal obstruction. This has been accomplished either by operation or by dilatation.

Many open surgical procedures have been designed to deal with achalasia, most of them plastic or anastomotic operations on the lower oesophagus and fundus of the stomach to overcome or bypass the obstruction at the sphincter. Heller (1914) proposed division of the circular muscle of the sphincter by two longitudinal incisions through the oesophageal wall down to the mucosa, from the dilated oesophagus above on to the stomach below. This sound procedure was neglected until a classic paper by Barrett and Franklin in 1949 awakened surgeons to the danger of oesophagitis in anastomotic procedures and revived interest in Heller's operation. The modification, in which a single longitudinal incision is used, has achieved widespread support and is almost invariably used.

There are conflicting reports on the results of surgical treatment, the incidence of gastrooesophageal reflux and oesophagitis, and the necessity for routine reconstruction of the oesophageal hiatus. The object of this paper is to review patients with achalasia who were treated in the Southampton Western Hospital under the care of one of us (KSM).

Between 1960 and 1973, 48 patients had surgical treatment for achalasia. Of the $\mathbf{4 8}$ patients, 17 were men. The average age of the whole group was 50.7 ; that of the men 41.6 and of the women $54 \cdot 7$. The age range was 12 to 82 years. The duration of symptoms at the time of diagnosis varied from a few months to 36 years, the average being 6.8 years in men and 7.8 years in women. In $17 \%$ of the patients the duration was a few months, although the disease may have been symptomless for much longer.

There was no close correlation between duration of symptoms and the degree of dilatation of the oesophagus, but in 21 patients with gross dilatation the duration of symptoms ranged from nine months to 36 years, with an average of 10.6 years; in 24 with moderate dilatation there was a range of five months to 35 years, with an average of four years; and in three with minimal dilatation with symptoms the duration was three months, one year, and 10 years. It seems that minor or moderate degrees of dilatation are a feature of the individual patient and are not directly related to duration, but that gross dilatation does gradually develop over a period of years in most cases.

The severity of the disease was classified according to the degree of oesophageal dilatation noted radiologically before operation. The disease was considered mild when there was little or no dilatation, moderate when there was dilatation to twice normal calibre or more, and severe when the oesophagus showed gross dilatation and lengthening.

Of the symptoms, dysphagia, though not necessarily the most prominent, was present in all patients. Regurgitation of oesophageal contents was found in 19 patients, and weight loss in 13. Pain was a symptom in 18 patients, of whom three had mild, 13 moderate, and two severe disease. Pain is thus found more frequently in the milder degrees of disease, suggesting that it is due to oesophageal spasm, a disorder of circular 
muscle contraction. In severe cases, pain seems to be due to pressure in the mediastinum from the grossly distended oesophagus.

Three patients described emotional disturbances accompanying the onset of achalasia. Emotional stress may cause deterioration of symptoms or may aggravate insidious symptoms previously tolerated subconsciously; this may be said of many diseases. Cough and other respiratory symptoms were noted in three patients and 'spill-over' pneumonia in five.

\section{TECHNIQUE}

We perform a modified Heller's operation transthoracically through the left seventh intercostal space. The lower part of the oesophagus is mobilized carefully so that the hiatus, its supporting structures, and the vagi are not damaged. A single longitudinal incision is made through the oesophageal wall down to the mucosa, from dilated oesophagus above on to stomach below. The lower oesophageal spincter is divided completely but we avoid any extension on to the gastric wall. The incision is never less than $5 \mathrm{~cm}$ in length and usually longer, up to 7 to $10 \mathrm{~cm}$. In mild cases, where there is little or no dilatation, the incision is carried up to the level of the aortic arch. No ill effects have followed these long incisions, but unsatisfactory results may follow incisions which are too short.

On the rare occasions that a frank hiatus hernia is found, or if the manipulations have disturbed the supporting structures around the hiatus, a hiatus hernia repair should be performed. If the hiatus is merely lax, then one or two sutures should be placed approximating the crura behind the oesophagus.

\section{CLINICAL EXPERIENCE}

Forty-eight patients were treated by oesophagomyotomy, and three patients who had had a previous oesophagomyotomy by an abdominal incision at other hospitals were treated by jejunal interposition because of recurrence of dysphagia.

Of the 48 patients treated by oesophagomyotomy, the mucosa was accidentally perforated in eight. The perforation was closed with fine interrupted sutures. In four, a hiatus hernia repair was carried out, and in seven, the crura were approximated behind the oesophagus. In two patients, small leiomyomata were excised from the lower oesophagus.

There were no hospital deaths and no significant postoperative complications; two patients developed thrombophlebitis and one a wound infection.

\section{RESULTS}

The follow-up period ranged from six months to 12 years with an average of $5 \cdot 8$ years. The results. were classified as excellent, good, fair or poor. $\overrightarrow{\vec{\omega}}$ Patients who were entirely symptom free and able ${ }_{\sigma}^{\omega}$ to eat any food without dysphagia were classed $\vec{x}$ as excellent. Those who suffered rare episodes of $\underset{\omega}{x}$ dysphagia or pain when eating certain foods, or $\stackrel{\circ}{\circ}$ on hurrying their meals, or when under stress, were classed as good. Those with residual dys- -0 phagia, less severe than before operation and ac-윽 ceptable to the patient, were classed as fair, andthose with deterioration, or no improvement, were응 classed as poor.

Table I summarizes the results of oesophagomyotomy in the 48 patients. Thirty-three obtained excellent results. Eleven had good results. They had moderate ( 7 cases) or mild (1 case) rather ${ }^{-1}$ than severe ( 3 cases) disease. These 11 experienced immediate dramatic relief of symptoms followed by the recurrence of occasional dys-0 phagia and pain, apparently due to obstructionő from irregular oesophageal contractions above the level of the sphincter, and these contractions ob $\overrightarrow{\overrightarrow{0}}$ struct the oesophagus as it regains its norma $B$ size. There was no progressive deterioration during their follow-up period, which ranged from? one to 12 years, with an average of $7 \cdot 3$ years.

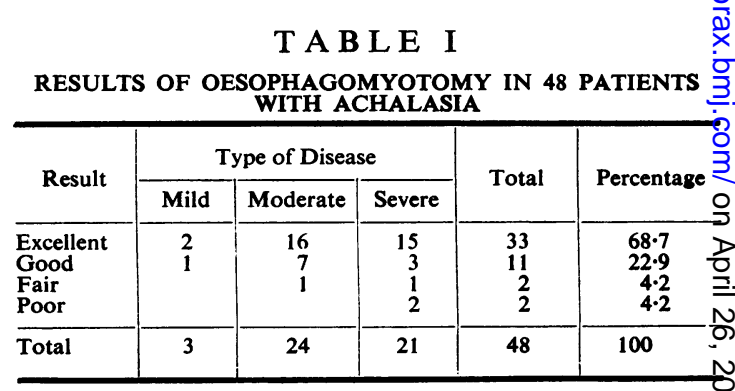

The result was fair in two patients. They hay persistent dysphagia but less than before operd tion. It was acceptable to them. The result was poor in two patients, and further operations wer $\$$ performed. The results in the eight patients in whom the mucosa was perforated were excellent in seven and good in one. There were no post operative complications. The results in the seve patients in whom the crura were approximatef were excellent in five, good in one, and fair in one. Of the four in whom a hiatus hernia repais 
was performed, three showed excellent and one good results.

Four patients developed oesophagitis after the Heller operation. The result was classified as poor in two of them, and further operations were performed. One, who had dysphagia and symptoms of oesophagitis, was classed as fair, and one who developed moderate reflux and slight to moderate oesophagitis, well controlled by conservative treatment (antacids and posture), was classed as good. $\mathrm{He}$ suffered no deterioration over a seven-year follow-up. Another patient has shown slight reflux on barium meal examination but has not developed oesophagitis during the 4-5-year follow-up. He leads a normal life and is symptom free.

FAILED HELLER OPERATION Inadequate Heller operations, followed by an immediate or late recurrence of dysphagia and associated with gross dilatation and elongation of the oesophagus, present a therapeutic problem. Dilatation of the cardia, or a further Heller operation, are unsatisfactory because the cardia is not at the most dependent point of the dilated oesophagus, and it cannot empty by gravity. Active emptying can be achieved by the interposition of an isoperistaltic jejunal transplant. Experience with these grafts in the treatment of peptic oesophageal stricture shows that they retain their peristaltic activity indefinitely. Three patients have been treated in this way, and their clinical details are summarized in Table II.

A left thoraco-abdominal approach through the seventh intercostal space is used. The oesophagogastric junction is divided, and the stomach is oversewn. The upper level of division of the oesophagus is selected so that the calibre of the oesophagus is compatible with that of the jejunal transplant. A suitable portion of upper jejunum, 7 to $10 \mathrm{~cm}$ in length, is isolated, pedicled on a branch of the superior mesenteric artery. It is transposed through the lesser sac to the hiatus, where it is anastomosed end to end to the oesophagus, and end to side to the posterior wall of the fundus of the stomach, away from and below the oversewn oesophagogastric junction. Half or more of the transplanted jejunum lies below the hiatus.

The postoperative course in all three patients was uncomplicated, and the results were excellent. All lead normal lives and are free of symptoms. They have been followed up for three years, two years, and four months respectively.

ASSOCIATION WITH CARCINOMA We have seen three examples of carcinoma with achalasia during the period of this review. A woman of 52, with a history of achalasia for 32 years, had an oesophagomyotomy at our hospital, with an excellent result, being symptom free for 10 years when she developed carcinoma of the oesophagus. A man of 53, with a 36-year history of achalasia, had an oesophagomyotomy at our hospital, which was succesful until four years after operation, when he developed carcinoma of the oesophagus. A man of 43 , with a three-year history of achalasia, developed carcinoma of the oesophagus. $\mathrm{He}$ had had no operative treatment for achalasia. There has been considerable discussion about the liability of patients with achalasia to develop carcinoma of the oesophagus. In this series there have been three cases. We believe that the incidence of carcinoma is higher among patients with achalasia and that a succesful Heller operation provides no insurance against its development.

\section{DISCUSSION}

Our results illustrate the excellent symptomatic relief which oesophagomyotomy provides for achalasia. Patients showing good results following surgery, do not deteriorate with the passage of

T A B L E I I

PATIENTS TREATED BY JEJUNAL INTERPOSITION

\begin{tabular}{|c|c|c|c|c|c|}
\hline \multirow{2}{*}{$\begin{array}{l}\text { Sex and Age } \\
\text { when first seen }\end{array}$} & \multicolumn{2}{|c|}{ At Other Hospitals } & \multicolumn{2}{|c|}{ At Southampton } & \multirow[b]{2}{*}{ Follow-up } \\
\hline & Treatment & Result & Treatment & Result & \\
\hline F 57 & $\begin{array}{l}\text { Abdominal Heller } \\
11 \text { yr previously }\end{array}$ & $\begin{array}{l}\text { Dysphagia recurred after } \\
3 \mathrm{mth} \text { with overspill }\end{array}$ & $\begin{array}{l}\text { Transthoracic } \\
\text { oesophagomyotomy } \\
\text { Dilatation } \\
\text { Jejunal interposition }\end{array}$ & $\begin{array}{l}\text { Deterioration of } \\
\text { dysphagia } \\
\text { Transient improvement } \\
\text { Excellent }\end{array}$ & $\begin{array}{l}2 \mathrm{yr} \\
3 \mathrm{yr}\end{array}$ \\
\hline F 57 & $\begin{array}{l}\text { Abdominal Heller } \\
8 \text { yr previously }\end{array}$ & $\begin{array}{l}\text { Dysphagia recurred after } \\
3 \mathrm{mth}\end{array}$ & $\begin{array}{l}\text { Transthoracic } \\
\text { oesophagomyotomy } \\
\text { Jejunal interposition }\end{array}$ & $\begin{array}{l}\text { Dysphagia recurred } \\
\text { after } 1 \frac{1}{2} \text { yr } \\
\text { Excellent }\end{array}$ & $\begin{array}{l}4 \mathrm{yr} \\
2 \mathrm{yr}\end{array}$ \\
\hline F 63 & $\begin{array}{l}\text { Abdominal Heller } \\
9 \text { yr previously }\end{array}$ & $\begin{array}{l}\text { Dysphagia recurred after } \\
7 \mathrm{yr}\end{array}$ & Jejunal interposition & Excellent & $4 \mathrm{mth}$ \\
\hline
\end{tabular}

All patients had gross dilatation and elongation of oesophagus at a time of jejunal interposition. 
time, as is usually the case after dilatation. The only change in the long-term results was in patients in whom immediate dramatic symptomatic relief following operation was followed by occasional or rare episodes of dysphagia or pain on eating certain foods, or when hurrying meals or when under stress. Radiological studies show that these episodes are due to oesophageal spasm at levels above the cardia, but always in the lower half of the oesophagus. These irregular contractions of the oesophagus are a feature of achalasia, but they are incapable of obstructing the dilated oesophagus. However, as the oesophagus reduces in calibre following succesful oesophagomyotomy at the cardia, irregular and forceful contractions in the lower half do become capable of obstructing the lumen and causing dysphagia and pain. It is to avoid the development of these late symptoms that we carry the oesophagomyotomy up to the level of the arch of the aorta in patients with minor degrees of dilatation of the oesophagus.

In the advanced stage of achalasia when the oesophagus is grossly dilated, elongated, and inert, oesophagomyotomy is indicated but the result is more likely to be good than excellent. The inert and atonic oesphagus must drain by gravity, and the lowest point may not be the cardia. If the result of oesophagomyotomy is poor, jejunal interposition, by providing an active emptying mechanism, gives an excellent result.

Thoracotomy provides the only adequate exposure of the lower oesophagus when oesophagomyotomy is to be carried out. The abdominal approach is inadequate and to be condemned. Through the chest it is possible to divide the lower oesophageal sphincter as far as the stomach wall without transecting the phreno-oesophageal ligament and with minimal disturbance of the other supporting structures of the hiatus; more important, this approach allows upward extension of the oesophagomyotomy to the level of the arch of the aorta, when there is little or no dilatation of the oesophagus.

It is not necessary to perform a hiatus hernia repair in every case. If there is an associated hiatus hernia, and this is rare, or if the manipulations have disturbed the supporting structures of the hiatus, then a repair can be performed. Suture of the crura behind the oesophagus, when the $\underline{\underline{E}}$ hiatus is wide, is more frequently required. There $\frac{\bar{\rho}}{\partial}$ are conflicting reports on the necessity for hiatus $\stackrel{\widetilde{Q}}{\circ}$ repair. Ellis et al. (1967) do not perform a hiatus? reconstruction in every case. Analysing 269 $\rightarrow$ oesophagomyotomies, they report symptomatic ${ }_{-}^{\circ}$ relief in $93 \%$ with an average six-year follow-up. $\vec{\omega}$ Their incidence of oesophagitis was low. They suggest that the myotomy be restricted to the $\vec{x}$ distal oesophagus, because a gastric extension of ${ }_{0}$ the incision does not help to relieve obstruction $i$ and may result in sphincteric incompetence.

The ease and safety of transthoracic oesophago- $C$ myotomy, and its excellent results, lead us to은 conclude that it is the best primary treatment for patients with achalasia and that it should be per-응 formed as soon as the diagnosis has been made. 0 The safety and success of the operation are suchळ that dilatation is obsolete.

\section{REFERENCES}

Barrett, N. R. and Franklin, R. H. (1949). Concern ing the unfavourable results of certain operationson performed in the treatment of cardiospasm. British Journal of Surgery, 37, 194.

Butin, J. W., Olsen, A. M., Moersch, H. J., and $\overrightarrow{\bar{\sigma}}$ Code, C. F. (1953). A study of esophageal pres-3 sures in normal persons and patients with cardiospasm. Gastroenterology, 23, 278.

Code, C. F. and Schlegel, J. F. (1963). The physiologic basis of some motor disorders of the esophagus. Surgical Physiology of Gastrointestinal Tract, by A. N. Smith, pp. 1-19.x Royal College of Surgeons, Edinburgh.

Ellis, F. H. Jr., Kiser, J. C., Schlegel, J. F., Earlam, R. J., McVey, J. L., and Olsen, A. M. (1967).ᄋ Esophagomyotomy for esophageal achalasia. Experimental, clinical, and manometric aspects. 0 Annals of Surgery, 166, 640.

Heller, E. (1914). Extramuköse Kardioplastik beimo chronischen Kardiospasmus mit Dilatation des Oesophagus. Mitteilungen aus den Grenzgebieter der Medizin und Chirurgie, 27, 141.

Kramer, P., Ingelfinger, J., and Atkinson, M. (1956). 응 The motility and pharmacology of the oesophagus in cardiospasm. Gastroenterologia, 86, 174.

Requests for reprints to: K. S. Mullard, FRCS $\frac{\mathrm{C}}{\mathrm{C}}$ Dickleburgh Hall, Diss, Norfolk IP21 4NT. 